\title{
Gold(III)pentafluorophenylarylazoimidazole: Synthesis and spectral (H, C, COSY, HMQC NMR) characterisation
}

\author{
PRITHWIRAJ BYABARTTA* and MARIANO LAGUNA \\ Departmento de Quimica Inorganica-Instituto de Ciencia deMateriales de Aragon, Universidad de \\ Zaragoza-CSIC, Zaragoza-50009, Spain \\ e-mail: prithwis33@yahoo.com
}

MS received 18 April 2006; revised 17 July 2006

\begin{abstract}
Reaction of $\left[\mathrm{Au}^{\mathrm{III}}\left(\mathrm{C}_{6} \mathrm{~F}_{5}\right)_{3}(\mathrm{tht})\right]$ with RaaiR' in dichloromethane medium leads to $\left[\mathrm{Au}^{\mathrm{III}}\left(\mathrm{C}_{6} \mathrm{~F}_{5}\right)_{3}\right.$ $\left.\left(\mathrm{RaaiR}^{\prime}\right)\right]\left[\mathrm{RaaiR}^{\prime}=p-\mathrm{R}-\mathrm{C}_{6} \mathrm{H}_{4}-\mathrm{N}=\mathrm{N}-\mathrm{C}_{3} \mathrm{H}_{2}-\mathrm{NN}-1-\mathrm{R}^{\prime},(\mathbf{1}-\mathbf{3}), \mathrm{R}=\mathrm{H}(\mathbf{a}), \mathrm{Me}(\mathbf{b}), \mathrm{Cl}\right.$ (c) and $\mathrm{R}^{\prime}=\mathrm{Me}(\mathbf{1})$, $\mathrm{CH}_{2} \mathrm{CH}_{3}(\mathbf{2}), \mathrm{CH}_{2} \mathrm{Ph}(3)$, tht is tetrahydrothiophen]. The nine new complexes are characterised by ES/MS as well as FAB, IR and multinuclear NMR $\left({ }^{1} \mathrm{H},{ }^{13} \mathrm{C},{ }^{19} \mathrm{~F}\right)$ spectroscopic studies. In addition to dimensional NMR studies as ${ }^{1} \mathrm{H},{ }^{1} \mathrm{H}$ COSY and ${ }^{1} \mathrm{H}{ }^{13} \mathrm{C}$ HMQC permit complete assignment of the complexes in the solution phase.
\end{abstract}

Keywords. Gold(I); 1-alkyl-2-(arylazo)imidazole; ${ }^{1} \mathrm{H},{ }^{13} \mathrm{C},{ }^{19} \mathrm{~F}$; COSY; HMQC NMR.

\section{Introduction}

Transition metal complexes of diimine and related ligands have attracted much attention. ${ }^{1-10}$ The recent years have witnessed a great deal of interest in the synthesis of the complexes of gold with $\alpha$-diimine type of ligands because of their photochemical and catalytic properties, energy conversion and ability to serve as building blocks in supramolecular arrays. ${ }^{11-17}$ Researchers have engaged in modifying the properties of Au-pyridine complexes by replacing the ligands at other donor centres, altering the steric and electronic properties of the ligands, and obtaining differently substituted polypyridine mixed-donor heterocycles. The search for suitable precursors to synthesize azoimine-complexes is a challenging task and the compounds are found to be useful in this context. ${ }^{6}$ Recently, we have developed the arylazoimidazole chemistry of ruthenium and have synthesised dichloro componds $\mathrm{RuCl}_{2}\left(\mathrm{RaaiR}^{\prime}\right)_{2}(\mathbf{4}-\mathbf{6})$ and diaquo species $\left[\mathrm{Ru}\left(\mathrm{OH}_{2}\right)_{2}\left(\mathrm{RaaiR}^{\prime}\right)_{2}\right]^{2+}\left[\mathrm{RaaiR}^{\prime}=p\right.$ $\mathrm{R}-\mathrm{C}_{6} \mathrm{H}_{4}-\mathrm{N}=\mathrm{N}-\mathrm{C}_{3} \mathrm{H}_{2}-\mathrm{NN}-1-\mathrm{R}^{\prime},(\mathbf{1}-\mathbf{3}), \mathrm{R}=\mathrm{H}, \mathrm{Me}, \mathrm{Cl}$ and $\mathrm{R}^{\prime}=\mathrm{Me}, \mathrm{CH}_{2} \mathrm{CH}_{3}, \mathrm{CH}_{2} \mathrm{Ph}$, abbreviated as $\mathrm{N}, \mathrm{N}^{\prime}$ chelators where $\mathrm{N}$ and $\mathrm{N}^{\prime}$ represent $\mathrm{N}$ (imidazole) and $\mathrm{N}$ (azo) respectively]. Syntheses of hetero-trischelates, $\left[\mathrm{Ru}(\mathrm{bpy})_{n}\left(\mathrm{RaaiR}^{\prime}\right)_{3-n}\right]\left(\mathrm{ClO}_{4}\right)_{2} \quad\left[\mathrm{bpy}=2,2^{\prime}-\right.$ bipyridine; $n=1,2$ ) from the solvento complexes

*For correspondence
$\left[\mathrm{Ru}\left(\mathrm{OH}_{2}\right)_{2}(\mathrm{bpy})_{2}\right]^{2+} /\left[\mathrm{Ru}\left(\mathrm{OH}_{2}\right)_{2}\left(\mathrm{RaaiR}^{\prime}\right)_{2}\right]^{2+}$ containing labile reaction centres are reported from Sinha's laboratory. ${ }^{4-10}$ Rhenium chemistry of this ligand system has been explored by A Chakravorty's group. Syntheses of molybdenum-bis-chelates with carbonyl, containing these ligand centres are reported from Ankermann's laboratory. However, gold and its organometallic chemistry with multinuclear NMR spectroscopy of this ligand system is totally unexplored. In this paper, we examine the reaction of RaaiR' on gold(III) pentafluorophenyl derivatives and the products are isolated. The complexes are well characterised by IR, ${ }^{1} \mathrm{H}$ NMR, ${ }^{13} \mathrm{C}$ NMR, ${ }^{1} \mathrm{H}-{ }^{1} \mathrm{H}$ COSY NMR, ${ }^{1} \mathrm{H}-{ }^{13} \mathrm{C}$ HMQC and mass spectrometry.

\section{Experimental}

\subsection{Materials and physical measurements}

Published methods were used to prepare RaaiR ${ }^{\prime}{ }^{7-9}$ $\left[\mathrm{Au}\left(\mathrm{C}_{6} \mathrm{~F}_{5}\right)_{3}(\mathrm{tht})\right]{ }^{17-20}$ All other chemicals and organic solvents used for preparative work were of reagent grade (SRL, Sigma Aldrich). The purification of $\mathrm{MeCN}$ used as solvent and other solvents was done following the literature method. ${ }^{8-14}$ Microanalytical data $(\mathrm{C}, \mathrm{H}, \mathrm{N})$ were collected using a Perkin-Elmer $2400 \mathrm{CHN}$ instrument (table 1). IR spectra were obtained using a Perkin-Elmer spectrophotometer $(\mathrm{KBr}$ disks, $\left.4000-350 \mathrm{~cm}^{-1}\right)$. The ${ }^{1} \mathrm{H}$ NMR spectra in 
Table 1. Microanalytical [found (calc.)] and IR spectral data

\begin{tabular}{|c|c|c|c|c|c|c|}
\hline \multirow[b]{2}{*}{ Compound } & \multirow[b]{2}{*}{$\mathrm{C}$} & \multirow[b]{2}{*}{$\mathrm{H}$} & \multirow[b]{2}{*}{$\mathrm{N}$} & \multicolumn{3}{|c|}{ IR } \\
\hline & & & & $v(N=N)$ & $v(\mathrm{C}=\mathrm{N})$ & $v\left(\mathrm{C}_{6} \mathrm{~F}_{5}\right)$ \\
\hline$\left[\mathrm{Au}\left(\mathrm{C}_{6} \mathrm{~F}_{5}\right)_{3}(\mathrm{HaaiMe})\right], \mathrm{C}_{28} \mathrm{H}_{10} \mathrm{~F}_{15} \mathrm{~N}_{4} \mathrm{Au}, \mathbf{1 a}$ & $\begin{array}{c}37 \cdot 59 \\
(37 \cdot 58)\end{array}$ & $\begin{array}{c}1 \cdot 12 \\
(1 \cdot 13)\end{array}$ & $\begin{array}{l}6 \cdot 28 \\
(6 \cdot 25)\end{array}$ & 1370 & 1590 & $1510,960,800$ \\
\hline$\left[\mathrm{Au}\left(\mathrm{C}_{6} \mathrm{~F}_{5}\right)_{3}(\mathrm{MeaaiMe})\right], \mathrm{C}_{29} \mathrm{H}_{12} \mathrm{~F}_{15} \mathrm{~N}_{4} \mathrm{Au}, \mathbf{1 b}$ & $\begin{array}{c}38 \cdot 32 \\
(38 \cdot 38)\end{array}$ & $\begin{array}{c}1 \cdot 31 \\
(1 \cdot 31)\end{array}$ & $\begin{array}{c}6 \cdot 10 \\
(6 \cdot 17)\end{array}$ & 1377 & 1597 & $1512,964,806$ \\
\hline$\left[\mathrm{Au}\left(\mathrm{C}_{6} \mathrm{~F}_{5}\right)_{3}(\mathrm{ClaaiMe})\right], \mathrm{C}_{28} \mathrm{H}_{9} \mathrm{~F}_{15} \mathrm{~N}_{4} \mathrm{AuCl}, \mathbf{1 c}$ & $\begin{array}{c}36 \cdot 12 \\
(36 \cdot 38)\end{array}$ & $\begin{array}{c}0.93 \\
(0 \cdot 98)\end{array}$ & $\begin{array}{l}6 \cdot 00 \\
(6 \cdot 01)\end{array}$ & 1377 & 1597 & $1512,964,806$ \\
\hline$\left[\mathrm{Au}\left(\mathrm{C}_{6} \mathrm{~F}_{5}\right)_{3}(\mathrm{HaaiEt})\right], \mathrm{C}_{29} \mathrm{H}_{12} \mathrm{~F}_{15} \mathrm{~N}_{4} \mathrm{Au}, \mathbf{2 a}$ & $\begin{array}{c}38 \cdot 32 \\
(38 \cdot 38)\end{array}$ & $\begin{array}{c}1 \cdot 31 \\
(1 \cdot 31)\end{array}$ & $\begin{array}{l}6 \cdot 10 \\
(6 \cdot 17)\end{array}$ & 1377 & 1597 & $1512,964,806$ \\
\hline$\left[\mathrm{Au}\left(\mathrm{C}_{6} \mathrm{~F}_{5}\right)_{3}(\mathrm{MeaaiEt})\right], \mathrm{C}_{29} \mathrm{H}_{12} \mathrm{~F}_{15} \mathrm{~N}_{4} \mathrm{Au}, \mathbf{2 b}$ & $\begin{array}{c}39 \cdot 03 \\
(39 \cdot 08)\end{array}$ & $\begin{array}{l}1 \cdot 53 \\
(1 \cdot 51)\end{array}$ & $\begin{array}{l}6 \cdot 05 \\
(6 \cdot 10)\end{array}$ & 1377 & 1597 & $1512,964,806$ \\
\hline$\left[\mathrm{Au}\left(\mathrm{C}_{6} \mathrm{~F}_{5}\right)_{3}(\mathrm{ClaaiEt})\right], \mathrm{C}_{29} \mathrm{H}_{11} \mathrm{~F}_{15} \mathrm{~N}_{4} \mathrm{AuCl}, \mathbf{2 c}$ & $\begin{array}{c}36 \cdot 92 \\
(38 \cdot 38)\end{array}$ & $\begin{array}{c}1 \cdot 17 \\
(1 \cdot 11)\end{array}$ & $\begin{array}{c}5 \cdot 91 \\
(5 \cdot 91)\end{array}$ & 1377 & 1597 & $1512,964,806$ \\
\hline$\left[\mathrm{Au}\left(\mathrm{C}_{6} \mathrm{~F}_{5}\right)_{3}(\mathrm{HaaiBz})\right], \mathrm{C}_{34} \mathrm{H}_{14} \mathrm{~F}_{15} \mathrm{~N}_{4} \mathrm{Au}, \mathbf{3 a}$ & $\begin{array}{c}42 \cdot 02 \\
(42 \cdot 03)\end{array}$ & $\begin{array}{c}1 \cdot 39 \\
(1 \cdot 38)\end{array}$ & $\begin{array}{c}5 \cdot 71 \\
(5 \cdot 717)\end{array}$ & 1377 & 1597 & $1512,964,806$ \\
\hline$\left[\mathrm{Au}\left(\mathrm{C}_{6} \mathrm{~F}_{5}\right)_{3}(\mathrm{MeaaiBz})\right], \mathrm{C}_{35} \mathrm{H}_{16} \mathrm{~F}_{15} \mathrm{~N}_{4} \mathrm{Au}, \mathbf{3 b}$ & $\begin{array}{c}42 \cdot 68 \\
(42 \cdot 66)\end{array}$ & $\begin{array}{l}1 \cdot 63 \\
(1 \cdot 63)\end{array}$ & $\begin{array}{c}5 \cdot 61 \\
(5 \cdot 71)\end{array}$ & 1377 & 1597 & $1512,964,806$ \\
\hline$\left[\mathrm{Au}\left(\mathrm{C}_{6} \mathrm{~F}_{5}\right)_{3}(\mathrm{ClaaiBz})\right], \mathrm{C}_{34} \mathrm{H}_{13} \mathrm{~F}_{15} \mathrm{~N}_{4} \mathrm{AuCl}, \mathbf{3 c}$ & $\begin{array}{c}40 \cdot 63 \\
(40 \cdot 68)\end{array}$ & $\begin{array}{c}1 \cdot 29 \\
(1 \cdot 31)\end{array}$ & $\begin{array}{l}5 \cdot 59 \\
(5 \cdot 6)\end{array}$ & 1377 & 1597 & $1512,964,806$ \\
\hline
\end{tabular}

$\mathrm{CDCl}_{3}$ were obtained on a Bruker $500 \mathrm{MHz}$ FT NMR spectrometer using $\mathrm{SiMe}_{4}$ as internal reference, $\mathrm{CFCl}_{3}$ (external ${ }^{19} \mathrm{~F}$ ). Mass spectra were recorded on VG Autospec FAB technique using 3-nitrobenzyl (NBA) as matrix.

2.2 Preparation of the complexes tris-(pentafluorophenyl)\{1-methyl-2-(p-tolylazo)imidazole\} aurate(III), [Au $\left(\mathrm{C}_{6} \mathrm{~F}_{5}\right)_{3}($ MeaaiMe $\left.)\right]$

Yellow dichloromethane solution of 1-methyl-2-( $p$ tolylazo)imidazole, $0.039 \mathrm{~g} \quad(0.20<\mathrm{mmol})$ was added to a colourless dichloromethane solution $\left(15 \mathrm{~cm}^{3}\right)$ of $\left[\mathrm{Au}\left(\mathrm{C}_{6} \mathrm{~F}_{5}\right)_{3}(\mathrm{tht})\right](0.0941 \mathrm{~g}, 0.20 \mathrm{mmol})$ slowly, dropwise, and the mixture was stirred at 343-353 K for $12 \mathrm{~h}$. The red solution that resulted was concentrated $\left(4 \mathrm{~cm}^{3}\right)$ and kept refrigerated overnight. The addition of hexane to the above red solution gave a precipitate which was collected by filtration, washed thoroughly with hexane to remove excess ligand and tht, and then dried in vacuo over pump overnight. Analytically pure complexes were obtained after chromatography over an alumina (neutral) column on eluting the red band with toluene-acetonitrile $(4: 1, v / v)$ and evaporating slowly in air. The yield was $0.088 \mathrm{~g}(80 \%)$. Fluorine NMR, ${ }^{19} \mathrm{~F}\left\{{ }^{1} \mathrm{H}\right\}$, ppm of $\mathbf{1 a},-121.76\left(\mathrm{~m}, \mathrm{~F}_{\text {ortho }}, 4 \mathrm{~F}\right),-121.01$ ( $\left.m, \mathrm{~F}_{\text {ortho }}, 2 \mathrm{~F}\right)$,
$-157 \cdot 11\left(t, \mathrm{~F}_{\text {para }}, 2 \mathrm{~F}\right),-157 \cdot 01\left(t, \mathrm{~F}_{\text {para }}, 1 \mathrm{~F}\right),-161 \cdot 21$ $\left(m, \mathrm{~F}_{\text {meta }}, 4 \mathrm{~F}\right),-161.52\left(m, \mathrm{~F}_{\text {meta }}, 2 \mathrm{~F}\right) ; \mathrm{FAB}$ mass, $M$ (\% abundance), 894 (10), ES/MS 578 (50\%); Fluorine $\mathrm{NMR},{ }^{19} \mathrm{~F}\left\{{ }^{1} \mathrm{H}\right\}$, ppm of $\mathbf{1 b},-122.76\left(\mathrm{~m}, \mathrm{~F}_{\text {ortho, }}\right.$ $4 \mathrm{~F}),-121.81\left(m, \mathrm{~F}_{\text {ortho }}, 2 \mathrm{~F}\right),-157.81\left(t, \mathrm{~F}_{\text {para }}, 2 \mathrm{~F}\right)$, $-157.91\left(t, \mathrm{~F}_{\text {para }}, 1 \mathrm{~F}\right),-161.61\left(m, \mathrm{~F}_{\text {meta }}, 4 \mathrm{~F}\right),-161.59$ ( $\left.m, \mathrm{~F}_{\text {meta }}, 2 \mathrm{~F}\right) ; \mathrm{FAB}$ mass, $M$ (\% abundance), 908 (10), ES/MS 578.7 (40\%); Fluorine NMR, ${ }^{19} \mathrm{~F}\left\{{ }^{1} \mathrm{H}\right\}$, ppm of 1c, $-121.96\left(m, \mathrm{~F}_{\text {ortho }}, 4 \mathrm{~F}\right),-121.81$ ( $m, \mathrm{~F}_{\text {ortho, }}$, $2 \mathrm{~F}),-157.91\left(t, \mathrm{~F}_{\text {para }}, 2 \mathrm{~F}\right),-157.01$ ( $\left.t, \mathrm{~F}_{\text {para }}, 1 \mathrm{~F}\right)$, $-161.91\left(m, \mathrm{~F}_{\text {meta }}, 4 \mathrm{~F}\right),-161.59\left(m, \mathrm{~F}_{\text {meta }}, 2 \mathrm{~F}\right)$; FAB mass, $M$ (\% abundance), 928.5 (10), ES/MS 578 $(50 \%)$; Fluorine NMR, ${ }^{19} \mathrm{~F}\left\{{ }^{1} \mathrm{H}\right\}$, ppm of $\mathbf{2 a},-121.66$ $\left(m, \mathrm{~F}_{\text {ortho }}, 4 \mathrm{~F}\right),-121.41\left(m, \mathrm{~F}_{\text {ortho }}, 2 \mathrm{~F}\right),-157.61(t$, $\left.\mathrm{F}_{\text {para }}, 2 \mathrm{~F}\right),-157.91\left(t, \mathrm{~F}_{\text {para }}, 1 \mathrm{~F}\right),-161.81\left(m, \mathrm{~F}_{\text {meta }}\right.$, $4 \mathrm{~F}),-161.92\left(m, \mathrm{~F}_{\text {meta }}, 2 \mathrm{~F}\right)$; FAB mass, $M$ (\% abundance), 908 (10), ES/MS 578.01 (20\%); Fluorine NMR, ${ }^{19} \mathrm{~F}\left\{{ }^{1} \mathrm{H}\right\}$, ppm of $\mathbf{2 b},-121.76\left(\mathrm{~m}, \mathrm{~F}_{\text {ortho }}, 4 \mathrm{~F}\right)$, $-121.51\left(m, \mathrm{~F}_{\text {ortho }}, 2 \mathrm{~F}\right),-157 \cdot 81\left(t, \mathrm{~F}_{\text {para }}, 2 \mathrm{~F}\right),-157 \cdot 61$ $\left(t, \mathrm{~F}_{\text {para }}, 1 \mathrm{~F}\right),-161.91\left(\mathrm{~m}, \mathrm{~F}_{\text {meta }}, 4 \mathrm{~F}\right),-161.72(\mathrm{~m}$, $\left.\mathrm{F}_{\text {meta }}, 2 \mathrm{~F}\right)$; FAB mass, $M$ (\% abundance), 922 (9), ES/MS 578 (40\%); Fluorine NMR, ${ }^{19} \mathrm{~F}\left\{{ }^{1} \mathrm{H}\right\}$, ppm of 2c, $-121.46\left(m, \mathrm{~F}_{\text {ortho }}, 4 \mathrm{~F}\right),-121.61$ ( $\left.m, \mathrm{~F}_{\text {ortho }}, 2 \mathrm{~F}\right)$, $-157.81\left(t, \mathrm{~F}_{\text {para }}, 2 \mathrm{~F}\right),-157.91\left(t, \mathrm{~F}_{\text {para }}, 1 \mathrm{~F}\right),-161.01$ $\left(m, \mathrm{~F}_{\text {meta }}, 4 \mathrm{~F}\right),-161.92\left(m, \mathrm{~F}_{\text {meta }}, 2 \mathrm{~F}\right)$; FAB mass, $M$ (\% abundance), 942.5 (17), ES/MS 578 (30\%); Fluorine NMR, ${ }^{19} \mathrm{~F}\left\{{ }^{1} \mathrm{H}\right\}$, ppm of $\mathbf{3 a},-121.46(\mathrm{~m}$, 
$\left.\mathrm{F}_{\text {ortho }}, 4 \mathrm{~F}\right),-121 \cdot 51\left(m, \mathrm{~F}_{\text {ortho }}, 2 \mathrm{~F}\right),-157 \cdot 81\left(t, \mathrm{~F}_{\text {para }}\right.$, $2 \mathrm{~F}),-157.91\left(t, \mathrm{~F}_{\text {para }}, 1 \mathrm{~F}\right),-161.88\left(\mathrm{~m}, \mathrm{~F}_{\text {meta }}, 4 \mathrm{~F}\right)$, $-161.32\left(m, \mathrm{~F}_{\text {meta }}, 2 \mathrm{~F}\right)$; FAB mass, $M$ (\% abundance), 970 (13), ES/MS 578 (30\%); Fluorine NMR, ${ }^{19} \mathrm{~F}$ $\left\{{ }^{1} \mathrm{H}\right\}$, ppm of $\mathbf{3 b},-121.76\left(m, \mathrm{~F}_{\text {ortho }}, 4 \mathrm{~F}\right),-121.71$ $\left(m, \mathrm{~F}_{\text {ortho }}, 2 \mathrm{~F}\right),-157 \cdot 81\left(t, \mathrm{~F}_{\text {para }}, 2 \mathrm{~F}\right),-157 \cdot 71\left(t, \mathrm{~F}_{\text {para }}\right.$, $1 \mathrm{~F}),-161.31\left(\mathrm{~m}, \mathrm{~F}_{\text {meta }}, 4 \mathrm{~F}\right),-161.72$ ( $\left.m, \mathrm{~F}_{\text {meta }}, 2 \mathrm{~F}\right)$; FAB mass, $M$ (\% abundance), 984 (16), ES/MS 578 $(60 \%)$; Fluorine NMR, ${ }^{19} \mathrm{~F}\left\{{ }^{1} \mathrm{H}\right\}$, ppm of $\mathbf{3 c},-121.46$ $\left(m, \mathrm{~F}_{\text {ortho }}, 4 \mathrm{~F}\right),-121.31$ ( $\left.m, \mathrm{~F}_{\text {ortho }}, 2 \mathrm{~F}\right),-157 \cdot 21(t$, $\left.\mathrm{F}_{\text {para }}, 2 \mathrm{~F}\right),-157.61\left(t, \mathrm{~F}_{\text {para }}, 1 \mathrm{~F}\right),-161.91\left(m, \mathrm{~F}_{\text {meta }}\right.$, $4 \mathrm{~F}),-161.62\left(m, \mathrm{~F}_{\text {meta }}, 2 \mathrm{~F}\right)$; FAB mass, $M$ (\% abundance), 1004.5 (17), ES/MS 578 (30\%).

\section{Results and discussion}

\subsection{Synthesis and formulation}

The complexes $\left[\mathrm{Au}\left(\mathrm{C}_{6} \mathrm{~F}_{5}\right)_{3}\left(\mathrm{RaaiR}^{\prime}\right)\right]$, were prepared in good yield $(65-85 \%)$ by removing tht from [Au $\left(\mathrm{C}_{6} \mathrm{~F}_{5}\right)_{3}$ (tht)] (tht = tetrahydrothiophen), with RaaiR' under stirring at $343-353 \mathrm{~K}$ in dichloromethane solution. The synthetic routes are shown in scheme 1 . The compositions of the complexes are supported by microanalytical results. The orange complexes are soluble in common organic solvents viz. acetone, acetonitrile, chloroform and dichloromethane but insoluble in $\mathrm{H}_{2} \mathrm{O}$, methanol and ethanol.

\subsection{Spectral studies}

Fast atom bombartment (FAB) mass spectra of the complexes were recorded in dichloromethane medium. In the mass spectra the best technique for these complexes is FAB using NBA as matrix. In all cases, the parent peak appears with abundance in the range of $10-15 \%$. Other spectroscopically soft techniques such as ES/MS show the [M-L] fragment (i.e., $\left.\left[\mathrm{Au}\left(\mathrm{C}_{6} \mathrm{~F}_{5}\right)_{3}\right]^{+}\right)$and once again the fragmentation

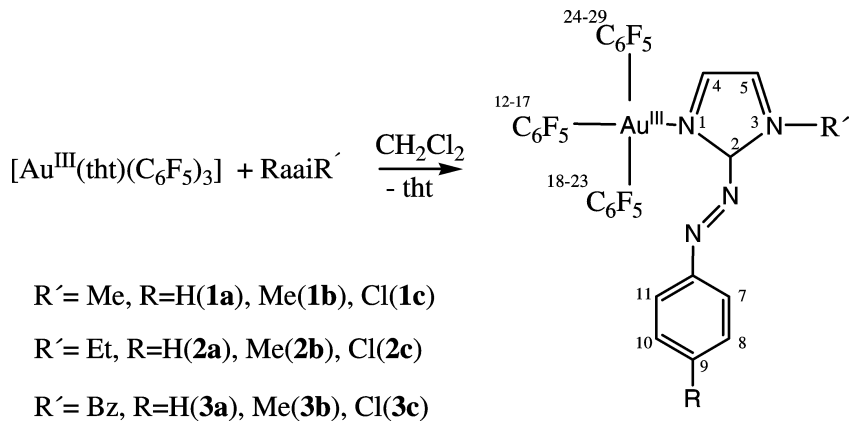

Scheme 1. unit (i.e., $\left.\left[\mathrm{Au}\left(\mathrm{C}_{6} \mathrm{~F}_{5}\right)_{2}\right]^{+}\right)$as the base peak of the spectra.

IR spectra of the complexes $\left[\mathrm{Au}\left(\mathrm{C}_{6} \mathrm{~F}_{5}\right)_{3}\left(\mathrm{RaaiR} \mathrm{R}^{\prime}\right)\right]$ show correspondence to the spectra of the parent tetrahydrothiophene analogue $\left[\mathrm{Au}\left(\mathrm{C}_{6} \mathrm{~F}_{5}\right)_{3}(\mathrm{tht})\right],{ }^{18,19} \mathrm{ex}-$ cept for the appearance of intense stretching at $1365-1370$ and $1570-1580 \mathrm{~cm}^{-1}$ with concomitant loss of $v(\mathrm{Au}-\mathrm{S}(\mathrm{tht}))$ at $320-340 \mathrm{~cm}^{-1}$. They are assigned to $v(\mathrm{~N}=\mathrm{N})$ and $\mathrm{v}(\mathrm{C}=\mathrm{N})$ respectively. Other important frequencies are $\mathrm{v}\left(\mathrm{C}_{6} \mathrm{~F}_{5}\right)$ at 1510-1520, 950-960 and 790-810 $\mathrm{cm}^{-1}$ along with weak bands at about 1070 and $1072 \mathrm{~cm}^{-1}$ due to the $v(\mathrm{C}-\mathrm{F})$ and $\mathrm{v}(\mathrm{C}=\mathrm{C})$ bond stretching of the pentafluorophenyl ring.

Fluorine NMR, ${ }^{19} \mathrm{~F}\left\{{ }^{1} \mathrm{H}\right\}$, (measured in $\mathrm{CDCl}_{3}$ ) provides a great deal of information about the present series of complexes. The fluorine atoms in each complex show six sharp signals corresponding to ortho, meta and para fluorine atoms, respectively, of the pentafluorophenyl ring of the complexes. Due to the trans/cis orientation, there are four ortho, two para, four meta fluorine atom (in the trans), whereas in the cis form the number is just half. Thus the spectra shows 2:1 intensity ratio, as trans (fluorine): cis (fluorine). This is the $\mathrm{AA}^{\prime} \mathrm{BB}^{\prime} \mathrm{C}$ type spin system, i.e. second-order spin system. On changing the substitution at $\mathrm{R}, \mathrm{R}^{\prime}$ on the ligand, there is a slight change in chemical shift values of these complexes. $^{14,18}$

The ${ }^{1} \mathrm{H}$ NMR spectra of $\left[\mathrm{Au}\left(\mathrm{C}_{6} \mathrm{~F}_{5}\right)_{3}\left(\right.\right.$ RaaiR') (1- $^{-}$ 3) complexes were unambiguously assigned (table 2 , figure 1) compared with the free ligand $\left(\operatorname{RaaiR}^{\prime}\right)^{7,9,11}$. The aryl protons $(7-\mathrm{H}-11-\mathrm{H})$ are shifted downfield by $0 \cdot 1-0.7 \mathrm{ppm}$ as compared to those of the parent derivatives. ${ }^{7-9}$ They are affected by substitution; 8and $10-\mathrm{H}$ are severely perturbed due to changes in the electronic properties of the substituents in the $\mathrm{C}(9)$-position. The aryl protons 7-(7'-) and 11-(11'-)H resonate asymmetrically, indicative of a magnetically anisotropic environment, ${ }^{7,8}$ even in the solution phase. The proton movement upon substitution (9$\mathrm{R})$ is corroborated with the electromeric effect of $\mathrm{R}$. The $1-\mathrm{R}^{\prime}\left[\mathrm{R}^{\prime}=\mathrm{Me}, \mathrm{CH}_{2} \mathrm{CH}_{3}, \mathrm{CH}_{2}(\mathrm{Ph})\right]$ exhibit the usual spin-spin interaction. 1-Me appears as a singlet at $4.2 \mathrm{ppm}$ for $\left[\mathrm{Au}\left(\mathrm{C}_{6} \mathrm{~F}_{5}\right)_{3}(\mathrm{RaaiMe})\right]$; the methylene protons, $1-\mathrm{CH}_{2}-\left(\mathrm{CH}_{3}\right)$ show $\mathrm{AB}$ type sextet $(\approx 4.4$, $4.6 \mathrm{ppm}, J=7-9 \mathrm{~Hz})$ and $\left(1-\mathrm{CH}_{2}\right)-\mathrm{CH}_{3}$ gives a triplet at $1.5 \mathrm{ppm}$ (coupling constant $=8.0 \mathrm{~Hz}$ ) for $[\mathrm{Au}$ $\left.\left(\mathrm{C}_{6} \mathrm{~F}_{5}\right)_{3}\left(\mathrm{RaaiCH} \mathrm{CH}_{3}\right)\right] ; 1-\mathrm{CH}_{2}(\mathrm{Ph})$ protons appear at $\mathrm{AB}$ type quartets $(\approx 5.5,5.7 \mathrm{ppm})$ with geminal coupling constant avg. $8.58 \mathrm{~Hz}$ in $\left[\mathrm{Au}\left(\mathrm{C}_{6} \mathrm{~F}_{5}\right)_{3}\right.$ 

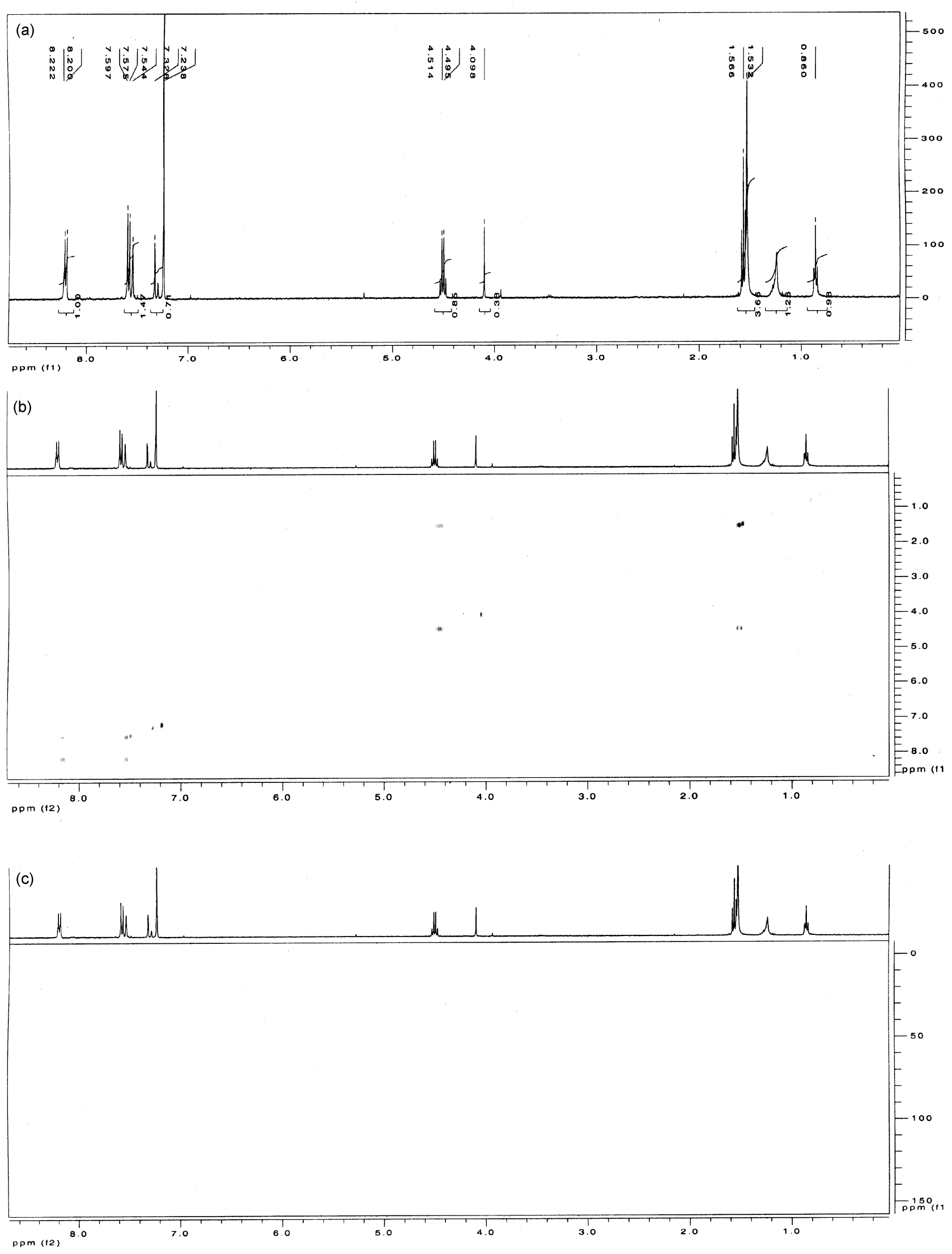

Figure 1. (a) H NMR, (b) H-H COSY NMR and (c) H-C HMQC NMR of complex 2c. 
Table 2. ${ }^{1} \mathrm{H}-\mathrm{NMR}$ spectral data, $\delta(\mathrm{J} / \mathrm{Hz})$, ppm of the complexes in $\mathrm{CDCl}_{3}$.

\begin{tabular}{|c|c|c|c|c|c|c|c|}
\hline Compound & $4-\mathrm{H}^{\mathrm{c}}$ & $5-\mathrm{H}^{\mathrm{c}}$ & $11-\mathrm{H}^{\mathrm{c}}$ & $7-\mathrm{H}^{\mathrm{c}}$ & $8,10-\mathrm{H}$ & $\mathrm{N}-\mathrm{CH}_{3}$ & $\mathrm{~N}-\mathrm{CH}_{2}$ \\
\hline$(\mathbf{1 a})^{\mathrm{a}}$ & $7 \cdot 15(7 \cdot 5)$ & $7 \cdot 06(7 \cdot 5)$ & $8 \cdot 03(8 \cdot 1)$ & $7 \cdot 99(8 \cdot 1)$ & $7.45(8 \cdot 1)^{\mathrm{d}}$ & $2 \cdot 09^{f}$ & \\
\hline (1b) & $6.98(7 \cdot 5)$ & $6 \cdot 86(7 \cdot 5)$ & $8 \cdot 17(8 \cdot 1)$ & $8 \cdot 04(8 \cdot 1)$ & $7 \cdot 34(8 \cdot 1)^{c}$ & $2 \cdot 17^{\mathrm{f}}$ & \\
\hline (1c) & $7 \cdot 13(8 \cdot 1)$ & $7 \cdot 02(8 \cdot 1)$ & $8 \cdot 15(7 \cdot 8)$ & $7.95(7 \cdot 8)$ & $7.55(7 \cdot 8)^{\mathrm{c}}$ & $2 \cdot 16^{\mathrm{f}}$ & \\
\hline$(2 \mathbf{a})^{\mathrm{a}}$ & $7 \cdot 14(7 \cdot 5)$ & $7 \cdot 00(7 \cdot 5)$ & $8 \cdot 01(7 \cdot 8)$ & $7 \cdot 85(7 \cdot 8)$ & $7 \cdot 45(8 \cdot 1)^{\mathrm{d}}$ & $1.52(8 \cdot 1)^{\mathrm{d}}$ & $4.42,4.55(10.0)^{\mathrm{e}}$ \\
\hline$(2 \mathbf{b})$ & $7 \cdot 33(8 \cdot 1)$ & $7 \cdot 24(8 \cdot 1)$ & $8 \cdot 11(7 \cdot 5)$ & $8 \cdot 04(7 \cdot 5)$ & $7.52(7.5)^{c}$ & $1.58(8 \cdot 1)^{\mathrm{d}}$ & $4.54,4.56(10.0)^{\mathrm{e}}$ \\
\hline (2c) & $7 \cdot 34(8 \cdot 1)$ & $7 \cdot 36(8 \cdot 1)$ & $8 \cdot 04(7 \cdot 5)$ & $7 \cdot 54(7 \cdot 5)$ & $7.46(7.5)^{c}$ & $1.55(8 \cdot 1)^{\mathrm{d}}$ & $4.54,4.53(11.0)^{\mathrm{e}}$ \\
\hline$(3 \mathbf{a})^{\mathrm{a}}$ & $7.06(7 \cdot 8)$ & $6.98(7 \cdot 8)$ & $8 \cdot 08(8 \cdot 1)$ & $8.00(8 \cdot 1)$ & $7 \cdot 48(8 \cdot 1)^{\mathrm{d}}$ & & $5.48,5.73(11.0)^{\mathrm{g}}$ \\
\hline$(3 b)$ & $6 \cdot 97(8 \cdot 1)$ & $6.99(8 \cdot 1)$ & $8 \cdot 21(8 \cdot 1)$ & $8 \cdot 10(8 \cdot 1)$ & $7 \cdot 10(8 \cdot 1)^{\mathrm{c}}$ & & $5.46,5.73(12.0)^{\mathrm{g}}$ \\
\hline (3c) & $7 \cdot 11(7 \cdot 8)$ & $7 \cdot 02(7 \cdot 8)$ & $8 \cdot 15(8 \cdot 1)$ & $8 \cdot 05(8 \cdot 1)$ & $7.58(8.1)^{\mathrm{c}}$ & & $5 \cdot 44,5 \cdot 70(13.0)^{\mathrm{g}}$ \\
\hline
\end{tabular}

${ }^{\mathrm{a}} \delta(9-\mathrm{H}) 7.60 \mathrm{ppm}(\mathrm{m}) ;{ }^{\mathrm{b}} \delta(9-\mathrm{Me}) ;{ }^{\mathrm{c}}$ doublet; ${ }^{\mathrm{d}}$ triplet; ${ }^{\mathrm{e}} \mathrm{AB}$ type quartet, geminal coupling constant; ${ }^{\mathrm{f}} 1-\mathrm{Me}$, singlet; ${ }^{\mathrm{g}} \mathrm{AB}$ type quartet, geminal coupling constant; ${ }^{\mathrm{h}}$ phenyl-H

Table 3. ${ }^{13} \mathrm{C}-\mathrm{NMR}$ spectral data of $\left[\mathrm{Au}\left(\mathrm{C}_{6} \mathrm{~F}_{5}\right){ }_{3}(\mathrm{RaaiR})\right]$ in $\mathrm{CDCl}_{3}$.

\begin{tabular}{|c|c|c|c|c|c|c|c|c|c|c|c|c|c|}
\hline & $2-C$ & $6-C$ & $4-C$ & $5-C$ & $7,11-\mathrm{C}$ & 8,10.-C & $9-\mathrm{C}$ & $\begin{array}{c}12,18 \\
24-C\end{array}$ & $\begin{array}{c}3,17,19 \\
23,25 \\
29-C\end{array}$ & $\begin{array}{c}14,16, \\
20,22, \\
26,28-C\end{array}$ & $\begin{array}{c}15,21 \\
27-C\end{array}$ & $9-R^{\prime}-C$ & $\begin{array}{l}\mathrm{N}-\mathrm{Me}, \\
\mathrm{Et}, \mathrm{Bz}\end{array}$ \\
\hline $1 \mathbf{a}$ & $140 \cdot 87$ & $139 \cdot 89$ & $120 \cdot 21$ & $122 \cdot 76$ & $130 \cdot 98$ & $128 \cdot 98$ & $127 \cdot 56$ & $148 \cdot 87$ & $150 \cdot 98$ & $145 \cdot 66$ & 144.99 & & $30 \cdot 98$ \\
\hline $1 b$ & $141 \cdot 87$ & $139 \cdot 89$ & $122 \cdot 21$ & $122 \cdot 76$ & 131.98 & $127 \cdot 98$ & $126 \cdot 56$ & $149 \cdot 87$ & 152.98 & $145 \cdot 66$ & 144.99 & $24 \cdot 45$ & 31.98 \\
\hline 1c & $140 \cdot 87$ & $139 \cdot 89$ & $120 \cdot 21$ & $122 \cdot 76$ & $130 \cdot 98$ & $128 \cdot 98$ & $137 \cdot 56$ & $148 \cdot 87$ & $150 \cdot 98$ & $145 \cdot 66$ & 144.99 & & $30 \cdot 08$ \\
\hline $2 \mathbf{a}$ & $141 \cdot 87$ & $139 \cdot 89$ & $121 \cdot 21$ & $123 \cdot 76$ & $131 \cdot 98$ & $127 \cdot 98$ & $127 \cdot 56$ & $147 \cdot 87$ & $151 \cdot 98$ & $144 \cdot 66$ & 144.99 & & $\begin{array}{l}30 \cdot 98 \\
41 \cdot 12\end{array}$ \\
\hline $2 b$ & $140 \cdot 87$ & 139.89 & $120 \cdot 21$ & $122 \cdot 76$ & $130 \cdot 98$ & $128 \cdot 98$ & $127 \cdot 56$ & $148 \cdot 87$ & $150 \cdot 98$ & $145 \cdot 66$ & $144 \cdot 99$ & $23 \cdot 33$ & $\begin{array}{l}31 \cdot 98 \\
42 \cdot 09\end{array}$ \\
\hline $2 c$ & $141 \cdot 87$ & $139 \cdot 89$ & $122 \cdot 21$ & $122 \cdot 76$ & 131.98 & $128 \cdot 98$ & $126 \cdot 56$ & $148 \cdot 87$ & $151 \cdot 98$ & $145 \cdot 66$ & 144.99 & & $\begin{array}{l}30 \cdot 98 \\
42 \cdot 65\end{array}$ \\
\hline $3 \mathbf{a}$ & $140 \cdot 87$ & $139 \cdot 89$ & $120 \cdot 21$ & $122 \cdot 76$ & $130 \cdot 98$ & 128.98 & $127 \cdot 56$ & $148 \cdot 87$ & $150 \cdot 98$ & $145 \cdot 66$ & 144.99 & & $\begin{array}{c}31 \cdot 98 \\
128-132\end{array}$ \\
\hline $3 \mathbf{b}$ & $141 \cdot 87$ & $138 \cdot 89$ & $121 \cdot 21$ & $122 \cdot 76$ & 131.98 & $128 \cdot 98$ & $125 \cdot 56$ & 148.87 & $151 \cdot 98$ & $145 \cdot 66$ & $145 \cdot 99$ & $22 \cdot 33$ & $\begin{array}{c}30 \cdot 98, \\
128-137\end{array}$ \\
\hline $3 c$ & $140 \cdot 87$ & $139 \cdot 89$ & $120 \cdot 21$ & $122 \cdot 76$ & $130 \cdot 98$ & 128.98 & $127 \cdot 56$ & $148 \cdot 87$ & $150 \cdot 98$ & $145 \cdot 66$ & 144.99 & & $\begin{array}{c}30 \cdot 98, \\
129-138\end{array}$ \\
\hline
\end{tabular}

( $\left.\left.\mathrm{RaaiCH}_{2} \mathrm{Ph}\right)\right]$. Imidazole 4- and 5-H appear as doublet at the lower frequency side of the spectra $(7 \cdot 0$ 7.2 ppm for 4-H; 6.9-7.1 ppm for 5-H). The aryl-Me $(\mathrm{R}=\mathrm{Me})$ in $\left[\mathrm{Au}\left(\mathrm{C}_{6} \mathrm{~F}_{5}\right)_{3}\left(\right.\right.$ Meaai $\left.\left.^{\prime}\right)\right]$ appears as a single signal at $1.55 \mathrm{ppm}$.

The ${ }^{13} \mathrm{C}$ NMR spectrum provides direct information about the carbon skeleton of the molecule. Assignments of different resonant peaks to respective carbon atoms are done for nine complexes (figure 2) and the data are given in table 3. Considering two arylazoimidazole moieties there are twenty-eight different carbon atoms in the molecule, which show different peaks in the ${ }^{13} \mathrm{C}$ NMR spectrum. Carbon atoms neighbouring the nitrogen atom shift downfield due to an increased electron density resulting from the presence of electronegative nitrogen atoms and $\pi$ electron delocalization in the magnetic environment. The non-protonated carbon atoms at $\mathrm{C}(2)$ and $\mathrm{C}(6)$ of the arylazoimidazole moiety is shifted farthest downfield in the spectrum $(\delta=170 \cdot 12 \mathrm{ppm}$ and $168 \mathrm{ppm}$ ) effected by the magnetic interaction of two bulky phenyl rings environment and the methyl, ethyl, benzyl substituted imidazole rings and the $\pi$ electron delocalization on the $=\mathrm{N}-\mathrm{CC}=\mathrm{N}-$ and $=\mathrm{N}-$ $\mathrm{C}-\mathrm{C}=\mathrm{C}-\mathrm{C}-$. Similarly, carbon atoms at $12,18,24$ positions on the $\mathrm{C}_{6} \mathrm{~F}_{5}$ molecule in the complex, resonant at lower fields of $\approx 165 \mathrm{ppm}$, resulting from the conjugative effect of the phenyl rings with the more electronegative fluorine atoms.

COSY spectra reveal the ${ }^{1} \mathrm{H}-{ }^{1} \mathrm{H}$ coupling interactions in the molecule. They are usually plotted as three-dimensional contours, where the conventional spectrum is represented along the diagonal (figure $1)$. The cross peaks along both the sides of the diagonal identify the nuclei that are coupled to one another. On the contrary, the protons that are 

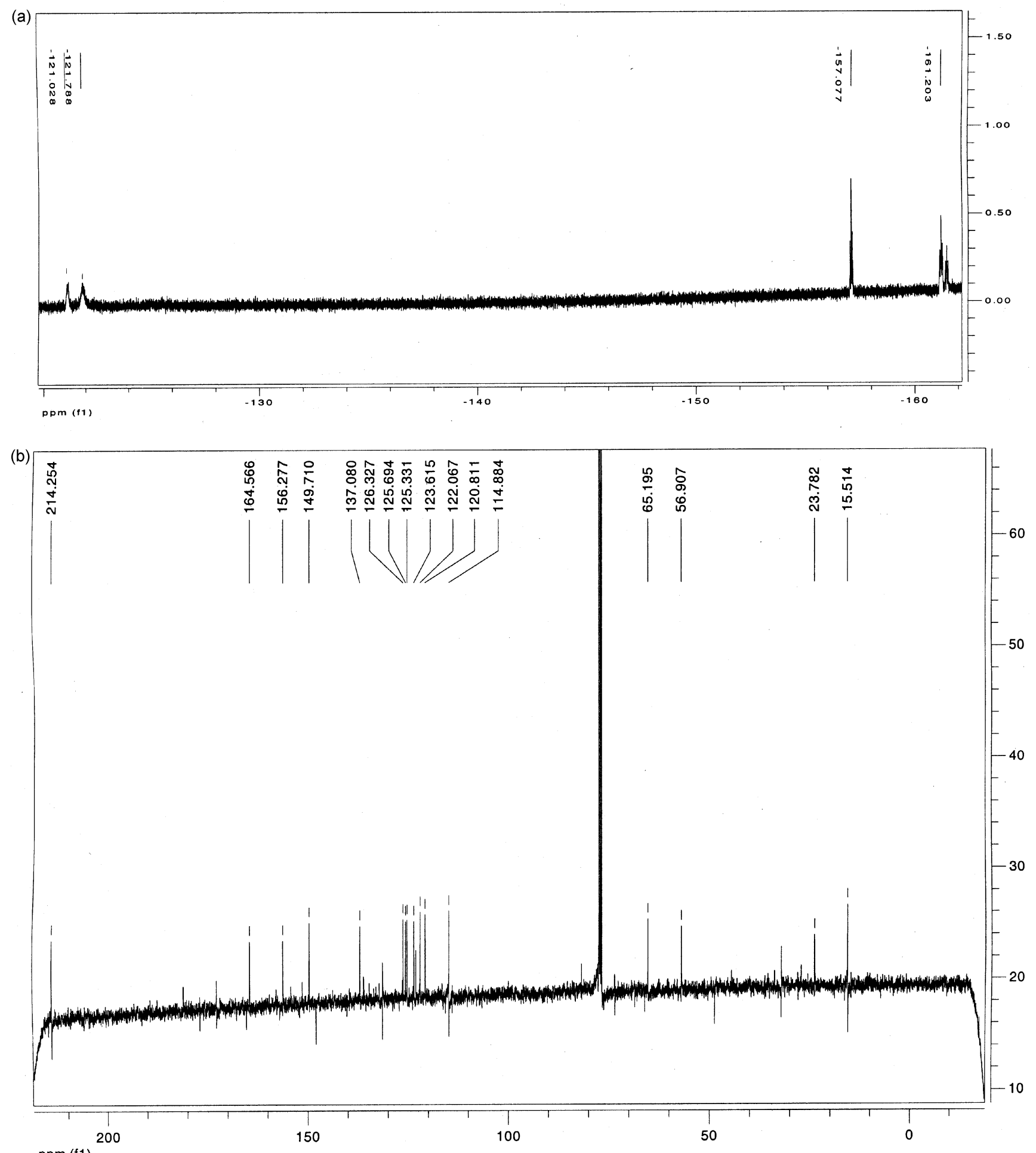

Figure 2. (a) F NMR of complex 2c, (b) C NMR of $\mathbf{3 b}$.

decoupled from the adjacent ones due to the lack of $\alpha$-protons show no correlation in the spectrum. For instance, in the COSY spectrum of the present complexes, absence of any off-diagonal peaks extending from $\delta=14.12 \mathrm{ppm}$ and $9.55 \mathrm{ppm}$ confirm their assignment of no protons on $\mathrm{N}(1)$ and $\mathrm{N}(3)$ respectively. However, extending horizontal and vertical lines from $\delta=8.32 \mathrm{ppm}[\mathrm{C}(\mathrm{a}) \mathrm{H}]$ and $868 \mathrm{ppm}$ 
$[\mathrm{C}(\mathrm{b}) \mathrm{H}]$ encounter cross peaks at $\delta=7 \cdot 12 \mathrm{ppm}$ and $7.23 \mathrm{ppm}$, where the $\mathrm{C}(7) \mathrm{H}$ and $\mathrm{C}(11) \mathrm{H}$ resonances are merged into multiplets along with the phenyl ring proton resonances. The comparatively weaker coupling interactions of $\mathrm{C}(8) \mathrm{H}$ and $\mathrm{C}(10) \mathrm{H}$ with the $\mathrm{C}(4) \mathrm{H}$ and $\mathrm{C}(5) \mathrm{H}$ protons of the imidazole moiety positioned far apart are shown by the poorly resolved cross peaks at $\delta=7.32 \mathrm{ppm}$ and $7.83 \mathrm{ppm}$. This also helps to assign phenyl and imidazole moiety protons to their respective values accurately, which is contrary to the expected greater downfield shift of $\mathrm{C}(11) \mathrm{H} \delta=7.92 \mathrm{ppm}$ of the RaaiR' molecule. COSY spectrum also turns out to be very helpful in the accurate assignment of proton resonance in the aromatic region. The doublet of the $\mathrm{C}(7) \mathrm{H}$ and $\mathrm{C}(11) \mathrm{H}$ protons show coupling interaction with the doublet at $\delta=7.12 \mathrm{ppm}$ and $7.68 \mathrm{ppm}[\mathrm{C}(8) \mathrm{H}$ and $\mathrm{C}(10) \mathrm{H}]$.

${ }^{1} \mathrm{H}-{ }^{13} \mathrm{C}$ heteronuclear multiple-quantum coherence (HMQC) spectra provide information regarding the interactions between the protons and the carbon atoms to which they are directly attached. Contrary to COSY, only the resultant interactions are plotted as contour peaks in the HMQC spectrum (figure 1). In the present complexes, the absence of any contours at $\delta=147 \cdot 12,160 \cdot 76,155.67 \mathrm{ppm}$ and $157.68 \mathrm{ppm}$ assign them to the $\mathrm{C}(2), \mathrm{C}(6), \mathrm{C}(12,18,24)$ and $\mathrm{C}(13-17,19-23$ and 25-29) carbon atoms respectively. This is because they belong to the non-protonated carbon atoms on the imidazole, phenyl and pentafluorophenyl rings. Thus they are unable to show any direct ${ }^{1} \mathrm{H}-{ }^{13} \mathrm{C}$ heteronuclear multiple-quantum coherence. The peaks observed at $\delta=144 \cdot 12$, $151 \cdot 76,155.67 \mathrm{ppm}$ and $147.68 \mathrm{ppm}$ assign them to the $\mathrm{C}(9), \mathrm{C}(8), \mathrm{C}(7), \mathrm{C}(11)$, and $\mathrm{C}(10)$ carbon atoms respectively, due to their interaction with $\mathrm{H}$ resonance at $\delta=7.42,7.55,7.82,7.80 \mathrm{ppm}$ and $7.38 \mathrm{ppm}$. The evidence for the presence of protons attached to the different types of carbon atoms in the spectra is obtained from the ${ }^{1} \mathrm{H}-{ }^{13} \mathrm{C}$ HMQC spectra. The doublets at $\delta=7.92,7.45,7.82 \mathrm{ppm}$ and $7.68 \mathrm{ppm}$ $[\mathrm{H}(7), \mathrm{H}(11), \mathrm{H}(8)$ and $\mathrm{H}(10)]$ show contours at $\delta=148.42,147.55, \quad 144.82 \mathrm{ppm}$ and $140.68 \mathrm{ppm}$ $[\mathrm{C}(7), \mathrm{C}(11), \mathrm{C}(8)$, and $\mathrm{C}(10)]$ which help to distinguish these carbon resonances, which are close to one another.

\section{Conclusions}

This work describes the isolation of $\left[\mathrm{Au}\left(\mathrm{C}_{6} \mathrm{~F}_{5}\right)_{3}\right.$ $\left(\right.$ RaaiR $\left.\left.^{\prime}\right)\right]$ and their spectral and elemental characterisation. ${ }^{19} \mathrm{~F}\left\{{ }^{1} \mathrm{H}\right\}$ NMR is very informative and they show six sharp signals which correspond to ortho, meta, para fluorine atom from the trans and cis pentafluorophenyl group. In the ${ }^{1} \mathrm{H}-{ }^{1} \mathrm{H}$ COSY spectra of the present complexes, absence of any off-diagonal peaks extending from $\delta=14.12 \mathrm{ppm}$ and $9.55 \mathrm{ppm}$ confirm their assignment of no proton on $\mathrm{N}(1)$ and $\mathrm{N}(3)$ respectively. Contour peaks in the ${ }^{1} \mathrm{H}-{ }^{13} \mathrm{C}$ HMQC spectrum in the present complexes, the absence of any contours at $\delta=147 \cdot 12,160 \cdot 76,155.67 \mathrm{ppm}$ and $157.68 \mathrm{ppm}$ assign them to the $\mathrm{C}(2), \mathrm{C}(6), \mathrm{C}(12)$ and $\mathrm{C}(13,14,15,16$ and 17$)$ carbon atoms respectively.

\section{Acknowledgements}

We thank the Ministerio de Ciencia y Technologia (Spain) for financial support and for a research grant to $\mathrm{PB}$.

\section{References}

1. Schmidbaur H, Grohman A and Olmos M E 1999 In Gold: Progress in chemistry, biochemistry and technology (Chichester: Wiley) p. 647, and references therein

2. Laguna M and Laguna A 1999 Coord. Chem. Rev. 193-195 837, and references therein

3. Gimeno M and Laguna A 1997 Chem. Rev. 97 511, and references therein

4. (a) Byabartta P 2005 Transition Met. Chem. 30 575; (b) Misra T K, Das D, Sinha C, Ghosh P K and Pal C K 1998 Inorg. Chem. 37 1672; (c) Byabartta P 2005 Transition Met. Chem. 30 672; (d) Deb A K, Paul P C and Goswami S 1988 J. Chem. Soc., Dalton Trans. 2051; (e) Deb A K and Goswami S 1991 Polyhedron 101799

5. Mondal B, Walewalkar M G and Lahiri G K $2001 \mathrm{~J}$. Chem. Soc., Dalton Trans. 4209

6. (a) Pal C K, Chattopadhyay S, Sinha C and Chakravorty A 1996 Inorg. Chem. 35 2442; (b) Sinha S, Das P K and Ghosh B K 1994 Polyhedron 13 2665; Sinha S, Banerjee A K and Ghosh B K 1997 Transition Met. Chem. 22483

7. Mondal B, Paul H, Puranik V G and Lahiri G K 2001 J. Chem. Soc., Dalton Trans. 481

8. (a) Das D $1998 \mathrm{Ph}$ D thesis, Burdwan University, Burdwan; (b) Misra T K, Santra P K and Sinha C 1999 Transition Met. Chem. 24672

9. Seal A and Ray S 1984 Acta Crystallogr. C40 929

10. Santra P K, Misra T K, Das D, Sinha C, Slawin A M Z and Woolins J D 1999 Polyhedron 182869

11. Chattopadhyay S, Ghosh K, Pattanayak S and Chakravorty A 2001 J. Chem. Soc., Dalton Trans. 1259

12. (a) Cotton F A and Wilkinson G 1994 Advanced inorganic chemistry 5th edn (New York: Wiley-Interscience) p. 338; (b) Greenwood N N and Earnshaw A 
1989 Chemistry of the elements (Oxford: Pergamon) p. 519

13. Chakravarty A R and Chakravorty A 1983 J. Chem. Soc., Dalton Trans. 961

14. Bardraji M P, Villasco A, Jimenez J, Jones P G, Laguna A, Laguna M and Merehan F 1994 Inorg. Chim. Aeta 223 55, and references therein

15. (a) Cerrada E, Fernandez E J, Gimeno M C, Laguna A, Laguna M, Terroba R and Villacampa M D 1995 J. Organomet. Chem. 492 105; (b) Bardraj M, Jones P G, Laguna A and Laguna M 1995 Organometallics 141310
16. (a) Uson R, Laguna A and Laguna M 1989 Inorg. Synth. 26 85; (b) Uson R, Laguna A and Vicente J 1976 J. Chem. Soc., Chem. Commun. 356

17. Uson R and Laguna A 1985 Organomet. Synth. 3325

18. Uson R, Laguna A, Laguna M, Jimenez J and Durana E 1990 lnorg. Chim. Acta 168 89, and references therein

19. Contel M, Jimenez L, Jones P G, Laguna A and Laguna M 1994 J. Chem. Soc., Dalton Trans. 2515, and references therein

20. Uson R, Laguna A, Laguna M, Jinenez J, Gomez M P, Silfinz A and Jones P G 1990 J. Chem Soc., Dalton Trans. 3457 